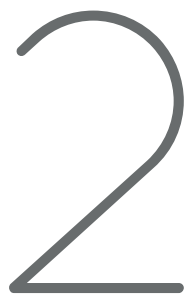

\title{
CULTURA POPULAR Y DISEÑO
}

\author{
Dr. Claudio Malo González
}


En uno de los cursos interamericanos para artesanos artífices que llevó a cabo el CIDAP, un artesano joyero, de indiscutibles habilidades y pericias arguyó con pertinacia, digna de mejor causa, cuán innecesarios eran los ejercicios en el área de morfología para, partiendo de un elemento natural o artificial, realizar los procesos de cambio que culminaban en una propuesta de diseño. Con un catálogo de joyas de Florencia en mano, pretendía reforzar su argumentación alegando que no tenía sentido perder el precioso tiempo con este tipo de ejercicios, si es que ya existían los diseños inclusive realizados. Ante la contra-argumentación del profesor respondió: "deme los materiales y las herramientas y le demostraré como puedo reproducir exactamente cualquier pieza que consta en el catálogo".

El punto de vista de este artesano joyero no es extraño ni excepcional en nuestro medio, es compartido por muchas personas, inclusive por "sabios" y "sabiondos" y si a alguien o algo hay que culpar por esta manera de pensar es a las centenas de años de dominación cultural que países como el nuestro -y en situación similar se encuentran otros de América Latina- han sufrido. Lo aceptable, lo bueno y lo óptimo no están, ni de lejos, en nuestras pobres e ignorantes tierras sino en Europa y en el gran país del norte, de manera que seremos tanto mejores cuanto mejor copiemos las bondades europeas y no tiene sentido pensar ni crear si es que otros ya lo han hecho y "nos han dado haciendo". Nadie discute la habilidad y capacidad para el trabajo de los latinoamericanos, de los ecuatorianos, pero la destreza de ésas, a veces, prodigiosas manos, hay que ponerlas al servicio de cerebros "superiores" como los de los europeos y norteamericanos.

Lo que antes se consideraba como indiscutible e incuestionable sentido común, ahora, a tiro de ballesta del año dos mil, por lo menos algunos sectores de nuestras sociedades califican como actitud aberrante, y se repite cada día con mayor insistencia e intensidad, que nuestros países deben hacer todo lo posible para rescatar y reforzar sus identidades nacionales, aunque en muchos casos la idea que se tiene de identidad nacional es vaga y difusa en extremo, si es que no errónea. De todas 
maneras, al margen de la precisión y de los matices del concepto, lo afirmado es positivo en cuanto hay por lo menos semillas de conciencia acerca de nuestra realidad y de nuestro destino. El reconocimiento de los hechos es el punto de partida de todo cambio.

\section{Cultura y Diseño:}

Como todo ser viviente, debe el hombre convivir con la realidad circundante, pero mientras en las demás especies animales hay una aceptación básica de las condiciones que les rodean y un proceso de adaptación a ellas, salvo cuando en forma limitada el instinto genera cambios, el comportamiento humano varía en la medida en que sistemáticamente busca e intenta -a veces con éxito, a veces fallidamentemodificar el medio de acuerdo con sus intereses. Esta sistemática modificación del entorno físico, unida a un permanente y cambiante proceso de elaboración de normas de comportamiento que regulen sus relaciones con sus semejantes, a conceptualizaciones de lo perceptible y lo no perceptible, a jerarquización variable de sistemas de valores, etc., conforman la cultura en el sentido antropológico de la palabra.

Entre las múltiples diferencias que entre el hombre y el animal existen, una plena de consistencia es la cultura en el sentido de que el ser humano es un animal capaz de crear cultura y luego organizar su comportamiento individual y colectivo de acuerdo con ese sistema de normas por él generado. Parte esencial a la cultura es el diseño y, si aceptamos la más difundida tesis para establecer el tránsito del simio al hombre: la sistemática elaboración de herramientas y utensilios, tendríamos que asumir que el ser humano hace su aparición en nuestro planeta diseñando, es decir como diseñador.

Ni es ésta la oportunidad ni el espacio de tiempo es suficiente para entrar en el laberinto de una definición de diseño en la que exista un amplio y, de ser posible, universal consenso. Partimos de un concepto muy general de Víctor Papanek: "Diseño es el esfuerzo consciente para establecer un orden significativo". Si diseñar presupone conciencia, es decir conocimiento de lo que se hace y de lo que se busca, y significado, es decir una relación medio-fin-medio lograda a través de un ordenamiento de los elementos con que se cuenta y de una secuencia de 
acciones que denominamos esfuerzo, diseñar es una actividad esencial y fundamentalmente cultural.

\section{Cultura y Culturas}

Todo lo que el hombre realiza lo hace en un "aquí" y en un "ahora", o sea en un espacio y en un tiempo determinados. Como no poseemos, salvo en nuestra imaginación que nos permite fugarnos de la realidad circundante, ni lámparas de Aladino ni varitas mágicas, nuestros quehaceres tienen que limitarse a aquellos elementos materiales y no materiales que el medio físico y lo que cada tiempo nos ofrece. Estas condiciones que oponen posibilidades y limitaciones a la creatividad humana no operan tan sólo a nivel individual sino también a nivel de colectividades, lo que trae como consecuencia que no podamos hablar de una| sola y homogénea cultura en la especie humana sino de muchas y diferenciadas culturas.

Las condiciones ecológicas son diferentes en los distintos lugares del planeta y las respuestas que el hombre da a sus condicionamientos no son necesariamente iguales en iguales nichos. Lo que se crea y cómo se crea es variable, de allí las diferencias de culturas. Pero además la cultura no es estática en la medida en que el hombre es un ente permanentemente insatisfecho. Las culturas cambian en el tiempo y condicionan, limitando y ofreciendo posibilidades, a la creatividad humana.

El diseño, por las razones que hemos mencionado anteriormente, no está, ni de lejos, exento de estas posibilidades y limitaciones, de allí que sus ordenamientos y realizaciones cambien al ritmo de los espacios y de los tiempos.

\section{Dependencia cultural}

Dotado de una inconmensurable capacidad de comunicación, los hombres no viven aisladamente en sus culturas cual tortugas en sus caparazones, hay un permanente intercambio de rasgos consistentes en la incorporación de elementos materiales y no materiales de lo gestado y perfeccionado en otras culturas, lo que da lugar a un proceso multiplicador de lo que el hombre crea, recrea y modifica. Si bien es verdad que en términos, teóricos cuando menos, no podemos hablar de 
culturas superiores e inferiores sino de culturas diferentes, en la práctica, la disponibilidad de más eficaces medios tecnológicos por parte de algunas, da lugar a un proceso de dominación y dependencia que, siendo inicialmente de orden bélico y económico, deviene luego en carácter cultural. En estos casos se inicia y refuerza la tendencia a ubicar en la cúpula de la jerarquía de valores de los pueblos dependientes aquellos que ocupan lugares similares en las culturas dominantes. Trasladado este fenómeno al campo del diseño, las culturas con mentalidad dependiente tienden a renunciar a la capacidad creativa y reemplazarla por la simple copia. Lo que en las culturas tecnológicamente avanzadas y dotadas de medios económicos más elevados se considera más funcional y estéticamente mejor logrado tiende a convertirse en un prototipo que en forma incondicional debe ser copiado. Los países denominados subdesarrollados, periféricos o dependientes se espera que, dentro de este contexto, manifiesten su capacidad y sus avances hacia el desarrollo, mientras más exactamente copien aquello que en las diferentes áreas del quehacer humano ha sido diseñado en las culturas avanzadas o desarrolladas.

Esta actitud parte de un principio erróneo: la renuncia a la creatividad del ser humano y a la búsqueda de realización de la colectividad partiendo de los elementos ecológicos y culturales y de las realizaciones culturales de quienes nos precedieron en el tiempo. El hombre se diferencia del animal por sus facultades creativas; por su capacidad para enfrentar las diferentes situaciones que los entornos material y no material le plantean, el ser humano resuelve problemas creativamente y si es que renuncia a esta facultad, en gran medida está renunciando a su hominidad. Diseñar es crear, es plantearse conscientemente el problema en medio de las circunstancias que lo generan y lo rodean,, es aislar ese problema, buscar soluciones, elaborar propuestas y buscar la manera de ponerlas en práctica. Copiar es simplemente poner las energías al servicio de otros cerebros, de otras motivaciones, de otras aspiraciones vitales. Es prescindir del crecimiento y del desarrollo autónomo.

\section{Identidad nacional}

Desde hace algunas décadas se habla $a_{\mathrm{r}}$ cada vez más con insistencia, de identidad nacional, de la necesidad de reforzarla y 
afianzarla, de expresarla tanto más frecuente y sistemáticamente mejor. Más allá de las: citas de este concepto -en ocasiones demagógicas y oportunistas- la noción de identidad nacional se fundamenta en el hecho de la diversidad de las culturas, diversidad que se patentiza en las peculiaridades' que los conglomerados humanos tienen. En este sentido, una política que pretende robustecer la identidad nacional tiene que tratar de proyectar sus acciones, en las múltiples esferas de la actividad partiendo en la medida de lo posible, de aquellas peculiaridades que culturalmente nos distinguen de otros conglomerados humanos- La antítesis de la identidad nacional es la dependencia mental que indefectiblemente deviene en copia. Aun suponiendo que políticas de este tipo, de sobrevaloración integral de lo foráneo y vergonzante desprecio de lo propio, de resultados material y económicamente más eficaces y objetivamente cuantificables, se estaría poniendo en práctica una repetitiva tendencia humana: priorización de lo material sobre lo no material, es decir, se estaría "vendiendo el alma al diablo" o la primogenitura por un plato de lentejas.

\section{Cultura popular y rasgos definitorios}

Aceptando este presupuesto, se plantean otros interrogantes: ¿En dónde se encuentran los rasgos culturales definitorios de nuestros pueblos?; ¿qué medidas deberían tomarse para que ellos sirvan de fundamento al desarrollo del conglomerado social?; ¿en qué medida se debe recurrir a ellos?; ¿hasta qué punto es factible realizar lo planificado? En términos generales, podríamos afirmar que los elementos definidores de nuestra identidad nacional se encuentran, en muy alta medida, en lo que denominamos "cultura popular", es decir en lo que a través de los años los sectores llamados populares de nuestra sociedad han venido creando y practicando para expresar sus apetencias vitales, sus concepciones de lo bello y lo feo y organizar sus vidas de acuerdo con sus ideas, creencias y cosmovisiones.

Nuestra condición de pueblos dependientes refuerza lo dicho en la medida en que en un pasado no lejano ni siquiera era coherente y lógico hablar de cultura popular ya que el término pueblo tenía como sinónimo vulgo, y lo realizado por el vulgo era vulgar, es decir ajeno y contrarío a la cultura. Nuestra sociedad se encontraba dividida básicamente en dos estamentos fundamentales: las élites, dueñas monopolíticas de la cultura, 
y el pueblo ajeno a ella o exclusivo propietario de la incultura. Las élites cultas acoplaban sus formas de comportamiento, usos, expresiones y realizaciones a lo que se hacía fuera, en Europa o en el norte; se era tanto más culto cuanto más hispanizado o afrancesado era el modo de vida. La cultura elitista, en consecuencia, carecía de creatividad y se limitaba a copiar lo hecho en otras partes, mientras que lo que hoy denominamos cultura popular, pese a su condición discriminada, hostilizada y agredida, era creativa y en consecuencia elaboradora de aquellos rasgos conformadores de nuestra identidad cultural.

Ajena a los mecanismos formales de transmisión de la cultura controlados por el poder político como la educación institucionalizada, los medios de comunicación, etc., la cultura popular sobrevivió gracias a la práctica permanente de sus rasgos, a la transmisión de generación a generación de los mismos, configurando mediante este proceso lo que hay en día denominamos tradición. Frente a la tradición, más aún si es que ésta abrumadoramente se encuentra en el campo de la llamada cultura popular, pueden darse dos posiciones contrapuestas: renunciar a ella considerándola una rémora, algo así como un lastre del pasado que frena e impide la proyección de las colectividades hacia el futuro. Este planteamiento se relaciona con un juicio despectivo hacia la cultura popular en el sentido de que el mejoramiento de las condiciones globales de vida sólo es posible gracias al progreso, y el progreso implica superación del pasado y desvinculación, lo más radical posible, de lo que suene a tradición.

La otra cara de esta moneda preconiza una preservación total e íntegra de la tradición, rechazando cualquier modificación, por pequeña que sea, que se pretenda llevar a cabo. El fundamento de este punto de vista se encuentra en el principio de que "cualquier tiempo pasado fue mejor" y de que, en consecuencia, todo cambio es sospechosamente negativo.

Ambas posiciones, por ser extremas, no son ni correctas ni constructivas. Un árbol consta de raíces, tallo, ramas, hojas, etc., y solamente sobrevive a plenitud si es que permanecen sus componentes integrales. Acudiendo a una analogía, si es que destruimos sus raíces (el pasado), el árbol muere; y, a la inversa, si es que sistemáticamente deterioramos su tallo y ramas, puede ocurrir lo mismo, existiendo la 
posibilidad de que la permanencia de las raíces puede dar lugar al retoño, es decir, a la revitalización de los componentes externos (presente). La posición correcta sería la de preservar la tradición, pero admitiendo las inevitables y muchas veces beneficiosas innovaciones. El ser humano vive siempre presente o presentes, pero los presentes indefectiblemente se encuentran configurados por el pasado, y muchos de los actos que realizamos en un momento dado cobran cabal sentido en virtud de hechos que se perfeccionarán en el futuro. Por mucho que nos empeñemos, no podemos vivir un presente desvinculado de las otras dos dimensiones. Lo que hemos dicho a nivel individual es válido, y quizás más a nivel social.

La tradición no puede conservarse tampoco como una mera reliquia carente de vigencia, algo así como una colección de piezas de un museo tradicional. La tradición se preserva, y es necesario tomar medidas apropiadas para ello, inserta en el presente y por lo tanto sujeta a la dinamia del cambio que es esencial al devenir temporal. Rasgos tradicionales del pasado están sujetos a la dinamia, ya que cultura que no cambia tiende a desaparecer. Evidentemente, en cierto sentido, el pasado está y no es posible modificarlo por ningún medio ni concepto, más aquellos rasgos al insertarse en el presente y proyectarse al futuro son susceptibles de modificación.

\section{Diseño y tradición}

Con estos antecedentes, y circunscribiéndonos al campo del diseño, el esfuerzo para establecer un orden significativo no puede partir de cero, de la nada, sino de elementos que la circunstancia espacio-temporal ofrecen, y dentro de estos elementos se encuentran aquellos que la tradición nos brinda, si diseñar en cuanto establecer un orden es cambiar, no cabe ni tiene sentido que éste se limite a una exacta reproducción del pasado. Quien reproduce con sorprendente exactitud una pieza de cerámica precolombina, no está diseñando sino copiando, al igual que el joyero que reproduce un modelo de una joya trabajada en estos días en Florencia.

La tradición, y en consecuencia la cultura popular, nos facilita una muy rica y amplia gama de elementos que pueden servir de punto de partida para diseño creativo. Si queremos afianzar nuestra identidad cultural, no podemos limitarnos a rescatar y conservar como reliquias del 
pasado aquello que el ser humano elaboró a lo largo de los años, sino que debemos partir de todas sus realizaciones para actualizarlas a las exigencias del presente y a las perspectivas del futuro. De trabajar con este criterio, dejaríamos de ser hábiles manos para cerebros ajenos y esa habilidad se instrumentalizaría para la creatividad de nuestros propios cerebros. Así nos volveríamos originales y alcanzaríamos personalidad cultural reconocida fuera de nuestra sociedad y encontraríamos caminos adecuados para labrar nuestra propia excelencia.

Por bien que un carpintero ecuatoriano trabaje muebles daneses, mejores serán los hechos por carpinteros daneses.

El mundo contemporáneo, en mayor grado que el del pasado, se caracteriza por la convivencia de contenidos de la cultura nacional y de la universal y de cambios y transformaciones en los que concurren los dos factores. Si desacertado fue renunciar a nuestros valores populares tradicionales y entregarse sin beneficio de inventario a los extranjeros, también se cometería el mismo pecado si pretendemos aislarnos a lo nuestro negándonos a admitir todo lo foráneo. Es conveniente tener muy en claro que la incorporación de la cultura popular al diseño no quiere decir la renuncia total a los contenidos de la cultura universal. Lo ideal es llegar a un justo y equilibrado término medio para hacer del diseño un proceso de ordenamiento consciente y significativo en que coexistan creativamente lo tradicional-popular y lo foráneo.

\section{Conclusiones}

Los ámbitos por los que incursiona el diseño son muchos y variados; evidentemente tiene que ver el diseño con la tecnología para elaborar máquinas, herramientas e instrumentos destinados a desempeñar funciones específicas. Mas lo que se ha dicho en esta ponencia, y lo que a continuación se dirá, tiene que ver más bien con los elementos estéticos de este proceso ordenador, los mismos que, en mayor o menor grado se dan en los diferentes objetos, simples o complejos que el ser humano crea y elabora.

1. En un mundo en el que hay un creciente y sistemático intercambio de elementos que los pueblos han creado a lo largo del tiempo, y continúan creando, es conveniente que las distintas sociedades 
expresen su identidad partiendo en sus creaciones de aquellos elementos culturales que les son peculiares, ya que renunciar a la identidad es convertirse en reproductores y copistas de lo que en otros conglomerados se ha hecho.

2. En países multiétnicos y multiculturales como el nuestro, encontramos una muy rica fuente de contenidos y de elementos que nos diferencian y peculiarizan en aquellos grupos humanos que sistemáticamente y a lo largo de siglos, han sido considerados como "incultos" y recibido un tratamiento discriminatorio y despectivo.

3. El proceso de mestizaje que se ha desarrollado a lo largo de siglos, no sólo implica intercambio y aparición de rasgos étnicos, sino también de contenidos culturales. En estas condiciones se han conformado elementos de cultura mestiza que sirven de fundamento para las normas de comportamiento, sistemas de valores $y$ parámetros de expresión de los denominados sectores populares.

4. Quienes han detentado los poderes político y económico desde que los españoles se establecieron en nuestros pueblos, han sobrevalorado como elementos culturales válidos aquellos rasgos generados y aceptados en Europa y otros países a tal punto de considerar como cultura solamente la imitación de ellos, minusvalorando aquellos elementos de nuestros sectores populares tanto indígenas como mestizos y excluyéndolos como parte de nuestras culturas.

5. El desarrollo de la Arqueología y de la Antropología Cultural en los siglos XIX y XX ha influido en la re valorización de los rasgos culturales indígenas y mestizos, dando lugar a que la cultura popular sea cada día más aceptada y se la considere como factor muy importante dentro de la identidad nacional.

6. Si aceptamos que es muy importante reforzar la identidad nacional de nuestros pueblos, es preciso que hagamos todo el esfuerzo posible por dejar de ser meros copiadores de los contenidos culturales foráneos, y nos empeñemos por hacer de la cultura popular de nuestro país un cuerpo respetable de elementos para diferentes acciones que tengan que realizarse. 
7. Siendo el diseño' una de las actividades que mejor contribuyen a conformar la imagen de una colectividad, sería plenamente deseable que la cultura popular sea un elemento fundamental en cuanto fuente de inspiración y punto de partida de los diseñadores.

8. En los planes y programas de estudio de las escuelas de diseño debe tomarse muy en cuenta la cultura popular para que los estudiantes, además de conocerla con claridad, aprendan a valorarla y a aplicarla en sus ejercicios.

9. Siendo la cultura dinámica, no cabe limitar el respeto a la cultura popular simplemente preservándola como un conjunto de elementos del pasado, sino que es menester incorporarla al presente y proyectarla al futuro; en este campo juega el diseño un papel fundamental.

10. La valorización de la cultura popular no implica la renuncia a la cultura universal; lo importante es, en el proceso de diseño, contar con elementos de ambos tipos. Lo universal y lo nacional, lo elitista y lo popular no se excluyen entre sí. El diseño, en cuanto ordenamiento creativo y significativo, debe partir de contenidos provenientes de diversas áreas. 